\title{
EFEKTIVITAS BLACK GARLIC UNTUK MENURUNKAN TEKANAN DARAH PADA PASIEN HIPERTENSI
}

\section{EFFECTIVITY OF BLACK GARLIC TO LOWER BLOOD PRESSURE IN HYPERTENSION PATIENT}

\author{
Annaas Budi Setyawan ${ }^{1 *}$, Siti Khoiroh Muflihatin² \\ *1Program Studi D III Keperawatan, Fakultas Kesehatan dan Farmasi, Universitas Muhammadiyah \\ Kalimantan Timur. Jalan Ir. H. Juanda No.15 Samarinda, email: abs564@umkt.ac.id, Indonesia \\ 2 Program Studi S1 IImu Keperawatan, Fakultas Kesehatan dan Farmasi, Universitas Muhammadiyah \\ Kalimantan Timur. Jalan Ir. H. Juanda No.15 Samarinda. email: siti.khoir96@gmail.com, Indonesia
}

\begin{abstract}
Background: Black Garlic is a fermented product of garlic that can be used as a herbal medicine for hypertension management. Based on the results of phytochemical analysis in black garlic There are several chemical content such as allicin, S-allyl Cystein, flavonoids, and hydrogen sulfide. The content of SAC, allicin, flavonoids and hidrogen sulfide in black garlic is a compound that can be used to lower blood pressure.

Objective: The objective of this research is to prove the effect of Black Garlic on reducing blood pressure in hypertensive patients.

Methods: The research method used a one group pretest and posttest design without a comparison group (control). The sample in this study were 15 people with hypertension in the work area of the Sempaja Public Health Center. To find out the difference in blood pressure with hypertension before and after being given a daily treatment of decoction of Black Garlic.

Results: The result of statistical test analysis showed that the variable systolic blood pressure of $p$-value is $0.001<0.05$, and diasttolic blood pressure of $p$-value is $0.000<0.05$.

Conclusion: The result showed that there was a significant influence on blood pressure before and after giving black garlic.
\end{abstract}

Keywords: Black Garlic, Blood Pressure, Hypertension

\section{PENDAHULUAN}

Hipertensi merupakan keadaan tekanan darah tinggi lebih dari 140/90 $\mathrm{mmHg}$ setelah dilakukan dua kali pengukuran tekanan darah secara terpisah (WHO). Saat ini, satu dari sepuluh penduduk dunia menderita hipertensi diatas usia 20-an, dan lima penduduk dari sepuluh penduduk di dunia pada usia di atas 30 tahun menderita hipertensi. Klasifikasi JNC VII terbaru mencantumkan klasifikasi prehipertensi, yaitu seseorang dengan tekanan sistolik 120-139 mmHg dan/atau diastolik 80-89 $\mathrm{mmHg}$, yang tidak digolongkan sebagai hipertensi. ${ }^{1}$
Hipertensi diperkirakan menjadi penyebab kematian sekitar 7,1 juta orang di seluruh dunia (sekitar 13\% dari total kematian). Di negara berkembang seperti Indonesia, terdapat beban ganda dari prevalensi penyakit hipertensi dan penyakit kardiovaskular lain bersama-sama dengan penyakit infeksi dan malnutrisi. $^{2}$

Hipertensi merupakan faktor risiko utama penyakit kardiovaskular, sehingga penurunan tekanan darah akan secara signifikan menurunkan angka risiko kejadian kardiovaskular. Disfungsi endotel, yang penyebabnya karena penurunan jumlah 
kecepatan dan penyerapan nitric oxide dalam darah. hal ini dapart menyebabkan faktor terjadinya hipertensi dan penyakit jantung lainnya. Bukti-bukti menunjukkan bahwa Nitric Oxide merupakan pemegang peran utama dalam regulasi tekanan darah. Gangguan penyerapan Nitric Oxide dapat menyebabkan arteri menjadi keras, yang merupakan penyebab tekanan darah tinggi. ${ }^{3}$

Provinsi Kalimantan Timur menempati urutan ke enam prevalensi penyakit jantung berdasarkan diagnosisi dokter pada penduduk semua umur. Menurut data dinas Kesehatan Kalimantan Timur penderita hipertensi di Kalimantan Timur pada usia $>18$ tahun sebanyak 88.967 jiwa (Profil Kesehatan Kalimantan Timur, 2016), sedangkan jumlah penderita hipertensi pada usia >18 tahun di Puskesmas Sempaja sebanyak 31.713 jiwa, menempati peringkat pertama pada Puskesmad di Wilayah Kecamatan Samarinda Utara pederita hipertensi. ${ }^{4}$

Penyembuhan tekanan darah tinggi bisa diobati dengan cara farmakologi dan non farmakologi. Pengobatan farmakologi biasanya memberikan efek samping bila penggunaannya dalam jangka waktu lama. Pengobatan non farmakologi salah satunya adalah penggunaan bahan alami berupa tumbuhan tanaman obat. Kandungan khasiat dan penggunaan tanaman herbal di Indonesia biasanya hanya berdasarkan pengalaman yang didapatkan dari orang terdahulu sehingga masih banyak tanaman herbal yang belum diteliti ilmiah. ${ }^{5}$

Biaya pengobatan cukup mahal dan memiliki efek samping jangka panjang yang membuat masyarakat lebih memilih terapi alternatif dengan beralih ke pengobatan tradisional. Hal ini dapat terjadi karena bahan berasal dari alam yang mudah diterima oleh tubuh dengan baik. Saat ini, obat-obat tradisional banyak dikembangkan untuk obat antidiabetik salah satunya yaitu bawang putih. ${ }^{6}$

Bawang putih (allium sativum) biasa digunakan di bidang penyembuhan dan pencegahan penyakit lebih dari 4000 tahun. Bawang putih memiliki manfaat untuk biologis dan farmakologis seperti anti tumorigenesis, anti pembekuan pembuluh darah stherosklerosis, modulasi gula darah dan antibiosis, penghambat pertumbuhan kanker. ${ }^{6}$

Bawang putih bisa diolah melalui cara fermentasi dan bisa berubah menjadi bawang putih hitam (black garlic). Bawang putih hitam atau black garlic merupakan suatu produk herbal dari bawang putih yang dipanaskan pada suhu antara $65^{\circ} \mathrm{C}-80^{\circ} \mathrm{C}$ dengan kelembapan antara $70-80 \%$ dari suhu kamar kurang lebih satu bulan. ${ }^{7}$

Selama dalam proses pemanasan, senyawa yang ada pada bawang putih tidak stabil dan tidak menyenangkan dalam bawang putih mentah diubah menjadi senyawa yang stabil serta tanpa rasa. Jadi pada umumnya bawang putih hitam (black 
garlic) memiliki rasa asam-manis tapi tidak ada bau yang menyengat. Dan selain itu bawang putih hitam tidak menyebabkan sakit perut atau gangguan pencernaan lainnya, memiliki aktivitas antioksidan yang lebih kuat dari bawang putih segar, dan dapat mencegah penyakit metabolic dan hepatotoksisitas beralkohol. ${ }^{8}$

Hasil riset didapatkan nilai TEAC antioksidan bawang putih dan black garlic adalah 13,3 \pm 0,5 dan 59,2 $\pm 0,8 \mu \mathrm{mol} / \mathrm{g}$ basah. Bawang putih hitam atau black garlic memiliki aktivitas anti oksidan lebih banyak dari bawang putih biasa sehingga bisa digunakan untuk mengobati penyakit hipertensi. $^{8}$

\section{BAHAN DAN CARA PENELITIAN}

Jenis design penelitian yang digunakan dalam penelitian ini yaitu pre eksperimen dengan design one group pretest and posttest tanpa kelompok pembanding, dimana dalam penelitian ini peneliti mengungkapkan hubungan sebab akibat dari Black Garlic dengan penurunan tekanan darah.

Teknik yang digunakan untuk pengambilan sampel menggunakan purposive sampling dengan jumlah 15 orang yang dibentuk menjadi satu kelompok, dengan kriteria inklusi pasien tinggal di wilayah kerja Puskesmas Sempaja Samarinda, pasien yang memiliki hipertenis bersedia menjadi responden dengan usia 3665 tahun, dan Tekanan darah : Sistolik (140-
$159 \mathrm{mmHg}$ ), Diastolik (90-99 mmHg). Kriteria eksklusi adalah pasien yang memiliki penyakit penyerta seperti DM, hiperkolesterolemia dan Hiperurisemia. Alat yang digunakan pada penelitian ini adalah alat ukur tensimeter aneroid dan stetoskop. ${ }^{9}$

Teknik pengampilan sampel dengan simpel random sampling yaitu melakukan pemilihan pasien yang akan dijadikan responden yang memenuhi kriteria inklusi dari peneliti. ${ }^{9}$

Penelitian ini dilakukan pada tanggal 4 17 Februari Tahun 2019 di wilayah kerja Puskesmas Sempaja Samarinda dengan sistem door to door dengan pemberian intervensi selama 2 minggu. Black Garlic diolah selama 18 hari dengan rice cooker. Kemudian Black Garlic diberikan kepada responden 2 siung / hari untuk dikonsumsi. ${ }^{10}$

Analisa data yang digunakan adalah analisa univariat dan analisa bivariat. Pada penelitian ini analisa univariat yang digunakan adalah distribusi frekuensi dan nilai rata-rata (mean). Analisa bivariat untuk menguji pengaruh pemberian black garlic terhadap perubahan tekanan darah sebelum dan sesudah diberikan intervensi menggunakan uji Wilcoxon Signed Rank.

Penelitian ini telah mendapatkan Surat Persetujuan Kelayakan Etik dari Komisi Etik Penelitian Kesehatan Fakultas Kedokteran Universitas Mulawarman dengan ethical clearance No: 06/KEPK-FK/II/2019.

\section{HASIL DAN PEMBAHASAN}

1. Karakteristik Responden 
Tabel 1. Karakteristik usia, jenis kelamin, pendidikan, dan pekerjaan di wilayah kerja

Puskesmas Sempaja Samarinda $(n=15)$

\begin{tabular}{|c|c|c|}
\hline $\begin{array}{l}\text { Karakteristik } \\
\text { Responden }\end{array}$ & Frekuensi & $\begin{array}{l}\text { Persentase } \\
(\%)\end{array}$ \\
\hline \multicolumn{3}{|l|}{ Usia } \\
\hline 36-45 tahun & 2 & 13.3 \\
\hline 46-55 tahun & 8 & 53.3 \\
\hline 56-65 tahun & 5 & 33.3 \\
\hline \multicolumn{3}{|l|}{ Jenis Kelamin } \\
\hline Laki-laki & 1 & 6.7 \\
\hline Perempuan & 14 & 93.3 \\
\hline \multicolumn{3}{|l|}{ Pendidikan } \\
\hline Tidak Sekolah & 2 & 13.3 \\
\hline SD & 10 & 66.7 \\
\hline SMP & 2 & 13.3 \\
\hline SMA & 1 & 6.7 \\
\hline \multicolumn{3}{|l|}{ Pekerjaan } \\
\hline Tidak Bekerja & 7 & 46.7 \\
\hline Pedagang & 5 & 33.3 \\
\hline Swasta & 1 & 6.7 \\
\hline Penjahit & 1 & 6.7 \\
\hline Petani & 1 & 6.7 \\
\hline Total & 15 & 100 \\
\hline
\end{tabular}

Sumber: Data Primer 2019

\section{Analisa Univariat}

a. Pre Test

Tabel 2 Distribusi Tekanan Darah Sistolik Sebelum Pemberian Black Garlic

\begin{tabular}{cccccc}
\hline Variabel & Mean & Median & SD & Min & Max \\
\hline Pre Test & 151.33 & 150.00 & 9.155 & 140 & 170 \\
\hline
\end{tabular}

Sumber : Data Primer 2019

Tabel 3 Distribusi Tekanan Darah Diastolik Sebelum Pemberian Black Garlic

\begin{tabular}{llllll}
\hline Variabel & Mean & Median & SD & Min & Max \\
\hline Pre Test & 102.67 & 100.00 & 5.936 & 100 & 120 \\
\hline Sumber : Data Primer 2019 & & &
\end{tabular}

Sumber : Data Primer 2019

b. Post Test

Tabel 4 Distribusi Tekanan Darah Sistolik Sesudah Pemberian Black Garlic

\begin{tabular}{llllll}
\hline Variabel & Mean & Median & SD & Min & Max \\
& & & & & \\
\hline Post Test & 130.67 & 130.00 & 4.577 & 120 & 140
\end{tabular}

Sumber : Data Primer 2019

Tabel 5 Distribusi Tekanan Darah Diastolik Sesudah Pemberian Black Garlic

\begin{tabular}{llllll}
\hline Variabel & Mean & Median & SD & Min & Max \\
\hline Post Test & 88.00 & 90.00 & 4.140 & 80 & 90 \\
\hline Sumber : Data Primer 2019
\end{tabular}

\section{Analisa Bivariat}

Tabel 6 Hasil statistik Analisa uji Wilcoxon Signed Rank Tekanan Darah Sistolik Dan Diastolik Sebelum dan Sesudah Pemberian Black Garlic

\begin{tabular}{lll}
\hline \multicolumn{1}{c}{ Variabel } & $\begin{array}{c}\text { Median } \\
\text { (Min-Max) }\end{array}$ & P-value \\
\hline TD sistolik & $150(140-170)$ & \\
pre test & & 0.001 \\
TD sistolik & $100(100-120)$ & \\
post test & & \\
\hline TD diastolik & $130(120-140)$ & \\
pre test & & 0.000 \\
TD diastolik $90(80-90)$ & \\
post test & & \\
Sumber : Data Primer 2019 &
\end{tabular}

Berdasarkan karakteristik sesuai dengan usia diketahui dari 15 responden, didapatkan sebagian besar dengan kategori usia lansia awal dengan jumlah 8 orang (53.3 $\%)$, kategori lansia akhir 5 orang (33.3\%), dewasa akhir (13.3 \%). Hasil penelitian ini sesuai dengan penelitian bahwa ada hubungan yang signifikan antara umur dengan kejadian tekanan darah tinggi yang tidak terkendali dengan $p$-value $=0.022<$ 0.05 . Berdasarkan hasil analisis yang diperoleh nilai $\mathrm{OR}=2.956$, artinya penderita dengan umur lebih dari 40 tahun memiliki resiko 9.956 kali mengalami tekanan darah tidak terkendali dibandingkan dengan penderita yang memiliki umur antara 18-40 tahun. ${ }^{11}$

Semakin usia seseorang bertambah maka akan terjadi penurunan fungsi fisiologis dan daya tahan tubuh yang dikarenakan proses penuaan yang dapat mengakibatkan seseorang rentan terkena penyakit yang salah satunya adalah hipertensi. ${ }^{11}$ Dari hasil penelitian ini, peneliti berasumsi bahwa 
semakin bertambahnya usia maka risiko terkena hipertensi juga meningkat yang dikarenakan terjadinya penurunan fungsi fisiologis dan daya tahan tubuh.

Berdasarkan karakteristik sesuai dengan jenis kelamin dengan kadar gula darah tinggi didapatkan sebagian besar adalah perempuan dengan jumlah 14 orang $(93.3 \%)$ dan laki-laki 1 orang (6.7\%). Hasil penelitian ini sejalan dengan penelitian, menyatakan bahwa perempuan cenderung lebih banyak menderita tekanan darah tinggi dibandingkan laki-laki dengan persentase sebanyak $27,5 \%$ perempuan mengalami tekanan darah tinggi, sedangkan pada lakilaki lebih rendah yaitu 5,6\%. ${ }^{12}$

Tekanan darah tinggi pada perempuan lebih rendah dibandingkan laki-laki pada usia muda. Perempuan yang belum mengaalami menopouse memiliki hormon pellindung yaitu estrogen yang berperan dalam meningkatkan HDL (High Densuty Lipoprotein). Perubahan hormon estrogen yang terjadi pada perempuan di usia lanjut ini dapat menyebabkan meningkatnya tekanan darah dan secara bertahap akan menetap serta lebih meningkat dari tekanan darah yang sebelumnya dan meningkatkan risiko terkena diabetes mellitus. ${ }^{13}$

Berdasarkan karakteristik sesuai pendidikan dari 15 responden, didapatkan sebagian besar pendidikan terakhir adalah SD sebanyak 10 orang (66.7\%), 2 orang (13.3\%) tidak bersekolah, 2 orang (13.3\%) SMP, 1 orang (6.7\%) SMA. Berdasarkan hasil penelitian yang menyataan bahwa banyak penyakit tekanan darah tinggi pada tingkat pendidikan rendah cenderung lebih tinggi dan menurun sesuai dengan meningkatnya pendidikan. Tingginya risiko terkena tekanan darah tinggi pada pendidikan yang rendah. $\mathrm{Hal}$ ini dapat disebabkan karena pengetahuan orang dengan ependidikan rendah terhadap kesehatan dan sulit atau lambat menerima informasi sehingga berdampak pada perilaku/pola hidup sehat. ${ }^{14}$

Berdasarkan karakteristik sesuai dengan pekerjaan dari 15 responden didapatkan sebagian besar tidak bekerja sebanyak 7 orang (46.7\%), 5 orang (33.3\%) Pedagang, 1 orang $(6.7 \%)$ swasta, 1 orang (6.7\%) Penjahit, 1 orang (6.7\%) Petani. Hasil penelitian ini sejalan dengan penelitian yang menyatakan bahwa pekerjaan rumah tangga merupakan salah satu penyebab stress yang dikarenakan beban yang banyak dan semakin berat, dan bukan hanya mengurus suami dan anak tetapi juga mengurus rumah setiap harinya. Dari hasil penelitian diatas, peneliti berasumsi bahwa latihan fisik yang kurang akan lebih berisiko terkena dibanding dengan orang-orang yang melakukan latihan fisik aktif karena latihan fisik sangat bagus untuk kesehatan tubuh. ${ }^{15}$

Dari hasil uji statistik menggunakan uji wilcoxon signed rank didapatkan didapatkan tekanan darah sistolik sebelum dan sesudah pemberian black garlic didapatkan nilai $p=$ $0.001(p<0.05)$, dan tekanan darah diastolik 
sebelum dan sesudah pemberian black garlic didapatkan nilai $p=0.000(p<0.05)$.

Hasil penelitian ini sejalan dengan penelitian dengan judul "Pengaruh Black Garlic Terharap Penurunan Tekanan Darah Pada Lansia Penderita Hipertensi Di Posyandu Lansia Dusun Patuk Lor Baturetno Kabupaten Wonogiri" didapatkan hasil uji paired $t$ test pada tekanan darah sistolik dengan nilai $p=0.000(p<0.05)$, dan hasil uji tekanan darah diastolik diketahui dengan nilai $p=0.001 \quad(p<0.05)$ sehingga dapat disimpulkan ada pengaruh pemberian black garlic terhadap tekanan darah penderita tekanan darah tinggi. ${ }^{16}$

Dimana mekanisme penurunan tekanan darah diperkirakan berkaitan erat dengan vasodilatsi otot pembuluh darah yang dipengaruhi oleh senyawa black garlic. Potensial membran otot polos mengalami penurunan hingga nilainya negatif dan ini menyebabkan tertutupnya $\mathrm{Ca} 2+-$ channel dan terbukanya $\mathrm{K}+-$ channel sehingga terjadilah hiperpolarisasi. Konsekuensi dari kondisi ini adalah otot pembuluh darah akan mengalami relaksasi. Diketahui kandungan dalam black garlic lebih tinggi dari bawang putih biasa yaitu $738,9 \mathrm{mg} / 100 \mathrm{~g} .{ }^{17}$

S-alyl cysteine (SAC) pada black garlic juga menunjukkan aktivitas antioksidan lebih tinggi daripada bawang putih segar. Black garlic memiliki SAC 2 kali lipat lebih tinggi dan tingkat DADS 30 kali lipat lebih tinggi dari bawang putih mentah. Selain mengandung S-allyl Cystein (SAC), didalam black garlic juga terdapat kandungan flavonoid, allicin dan hydrogen sulfide. ${ }^{17}$ Dimana allicin berguna untuk memblokir aktivitas angiotensin II, flavonoid dan hydrogen sulfida dapat melebarkan pembuluh darah yang mampu mengontrol tekanan darah sehingga dapat menurunkan tekanan darah. ${ }^{18}$

Selain untuk menurunkan tekanan darah, flavonoid memiliki sifat antioksidan yang dapat menurunkan resistensi insulin, meningkatkan sensitivitas insulin serta memperbaiki sel-sel beta pankreas yang dapat membersihkan radikal bebas yang berlebih sehingga mencegah komplikasi terkena hipertensi. ${ }^{18}$

Peneliti berasumsi, bahwa setelah pemberian black garlic selama 2 minggu tekanan darah responden terlihat turun dari sebelum diberikan black garlic. Dimana responden tidak ada mengeluh saat mengkonsumsi black garlic yang diberikan oleh peneliti dan penurunan tekanan darah yang terjadi dipengaruhi oleh kandungan dalam black garlic yaitu S-allyl Cystein (SAC), allicin, hydrogen sulfida, dan flavonoid.

\section{KESIMPULAN}

Black garlic terbukti efektif menurunkan tekanan darah sistol dan diastole pada penderita hipertensi.

\section{TERIMA KASIH}

1. Prof. Bambang Setiaji, Rektor Universitas Muhammadiyah Kalimantan Timur, Jl. Ir. H. Juanda No.15 
Samarinda, Telp: 0541-74811, email: umkt@umkt.ac.id

2. Husni Thamrin, Ph.D, Ketua LPPM Universitas Muhammadiyah Kalimantan Timur atas hibah Penelitian Kompetitif dengan No. kontrak: 326.5/LPPM/A.4/C/2018, Jl. Ir. H. Juanda No.15 Samarinda, Telp: 054174811, email: Ippm@umkt.ac.id

3. drg. Aprillia Lailati, Kepala UPT Puskesmas Sempaja Samarinda, JI. KH.Wahid Hasyim I Samarinda, Telp: 0541-220347, email: pkmsempaja@yahoo.com

\section{KEPUSTAKAAN}

1. ADA. Journal American Diabetes Association Standartds of Medical Care In Diabetes. 2017

2. Anggara, FHD., dan Prayitno, N. Faktor-Faktor yang Berhubungan dengan Tekanan Darah di Puskesmas Telaga Murni, Cikarang Barat Tahun 2012. Program Studi S1 Kesehatan Masyarakat STIKes MH. Thamrin. Jakarta. Jurnal IImiah Kesehatan. 2015. 5(1):20-25

3. Artiyaningrum, Azam. Faktor-Faktor Yang Berhubungan Dengan Kejadian Hipertensi Tidak Terkendali Pada penderita Yang melakukan Pemeriksaan Rutin. IImu Mesehatan Masyarakat. Fakultas IImu Keolahragaan. Universitas Negeri semarang, Indonesia. 2016. Public Health Perspective Journal 1 (1)

4. Dinas Kesehatan (DinKes). Gerakan Masyarakat Sehat. Dinas Kesehatan Kalimantan Timur. 2017.

5. Setyawan. A.B Efektivitas Teh Bawang Dayak untuk Menurunkan Kadar Gula Darah Pasien Diabetes Mellitus Tipe 2. STRADA Jurnal IImiah Kesehatan 2018. 7 (2), 7-13

6. Ryu, Ji Hyeon and kang, Dawon. Physicochemical Properties, Biological Avtivity, Health Benefits, and General Limitations of Aged Black Garlic: A Review. 2017

7. Ndraha, S., Diabetes Mellitus Tipe II dan Tatalaksana Terkini. 2014. Medicinus 9. 27:3-5.
8. Bae, S. E., Cho, S. Y., Won,Y. D.,Lee, S.H., \& Park, H.J. Changes in Sallylcysteine contents and physicochemicalmproperties of black garlic during heat treatment. LWT-Food Science and Technology. 2014. 55(1),397-402.

9. Dahlan, S. M. Besar Sampel dan cara Pengambilan Sampel. Jakarta: Salemba Medika. 2013

10. Young-Min Lee, Oh-CheonGweon, Young-JuSoeet al. Antioxidant effect of garlic and aged black garlic in animal model of type 2 diabetes mellitus. The Korean Nutrition Society and the Korean Society of Community Nutrition. 2009

11. Christi dkk. Hubungan Antara Umur dan Aktivitas Fisik dengan Derajat Hipertensi Di Kota Sulawesi Utara. Jurnal Kesmas. 2018. Vol. 7, No. 5.

12. Kemenkes RI. Profil Kesehatan Indonesia Tahun 2016.

13. National Institute for Diabetes and Digestive and Kidney Diseases (NIDDK). Cause of Diabetes. NIH Publication.2014

14. PERKENI. Konsensus Pengelolaan Diabetes Mellitus Tipe 2 di Indonesia 2011. Semarang: PB PERKENI. (2011).

15. Setyawan, A. B. Efektivitas Teh Bawang Dayak Untuk Menurunkan Kadar Gula darah Pasien Diabetes Mellitus Tipe II. Jurnal IImiah Kesehatan. 2018. Vol. 7, No. 2, November 2018.

16. Sutanto. Cekal (Cegah dan Tangkal) Penyakit Modern. Yogyakarta: C.V Andi Offset. 2010.

17. Wang H, Li X, Liu S, Jin S. (2010). Quantitative determination of allicin in Allium sativum $\mathrm{L}$. bulbs by UPLC. Chromatographia. 2010. 71(1-2):159162

18. Colin,Gonzale et.al. The Antioxidant Mechanisms Underlying The Aged Garlic Extract- And S-AllylcysteineInduced Protection. 2012 